10-2018

\title{
Is it safe? The restraint chair compared to traditional methods of restraint: $A$ three hospital study
}

Nicole Visaggio

Kathryn Phillips

Fairfield University, kphillips1@fairfield.edu

Kristen Kichefski

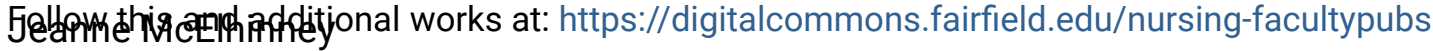
Copyright 2018 Elsevier

Themaskutty $\mathrm{B}_{\mathrm{t}}$ - dicull|la

(C) 2018. This manuscript version is made available under the CC-BY-NC-ND 4.0 license

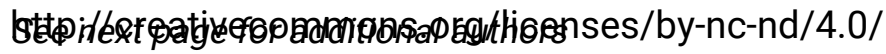

\section{Peer Reviewed}

\section{Repository Citation}

Visaggio, Nicole; Phillips, Kathryn; Kichefski, Kristen; McElhinney, Jeanne; Idiculla, Thomaskutty B.; Blair, Ellen W.; Johnson, Richard; Santaniello, Jamie; Pennant, Luciana RA; and Young, Scott C., "Is it safe? The restraint chair compared to traditional methods of restraint: A three hospital study" (2018). Nursing and Health Studies Faculty Publications. 184.

https://digitalcommons.fairfield.edu/nursing-facultypubs/184

\section{Published Citation}

Visaggio, N., Phillips, K. E., Kichefski, K., McElhinney, J., Idiculla, T. B., Blair, E. W., ... \& Young, S. C. (2018). Is it safe? The restraint chair compared to traditional methods of restraint: A three hospital study. Archives of Psychiatric Nursing 32(5), pp. 723-728. doi:10.1016/j.apnu.2018.04.003.

This item has been accepted for inclusion in DigitalCommons@Fairfield by an authorized administrator of DigitalCommons@Fairfield. It is brought to you by DigitalCommons@Fairfield with permission from the rightsholder(s) and is protected by copyright and/or related rights. You are free to use this item in any way that is permitted by the copyright and related rights legislation that applies to your use. For other uses, you need to obtain permission from the rights-holder(s) directly, unless additional rights are indicated by a Creative Commons license in the record and/or on the work itself. For more information, please contact digitalcommons@fairfield.edu. 


\section{Authors}

Nicole Visaggio, Kathryn Phillips, Kristen Kichefski, Jeanne McElhinney, Thomaskutty B. Idiculla, Ellen W. Blair, Richard Johnson, Jamie Santaniello, Luciana RA Pennant, and Scott C. Young 
Title: Is it safe? The restraint chair compared to traditional methods of restraint: A three hospital study

Authors: Nicole Visaggio, RN, BSN, Kathryn E. Phillips, PhD, APRN, NP-BC, Kristen Kichefski, MSN, MBA, RN-BC, Jeanne McElhinney, MS, RN-BC, Thomaskutty B. Idiculla, $\mathrm{PhD}$, Ellen W. Blair, DNP, APRN, PMHCNS-BC, NEA-BC, Richard Johnson, MHA, RN, Jamie Santaniello, MSN, APRN, PMHNP-BC, Luciana R. A. Pennant, BA, Scott C. Young, RN 


\section{Introduction}

The use of seclusion and restraint in inpatient psychiatric care has been the subject of ethical debate for decades, prompting the movement toward reduction of the practices. Risks inherent to seclusion and restraint, including negative physical and psychological effects for both patients and staff, have been extensively studied (Kontio et al., 2010). Historically, restraint has included physical holds and four-point mechanical restraint while seclusion is defined as isolation in a locked quiet room. Despite the success of reduction programs, situations continue to occur in which seclusion or restraint is initiated as an intervention to maintain the safety of staff and patients when imminent danger exists (Moylan \& Cullinan, 2011). The ethical dilemma faced by nurses who must maintain safety while reducing the risk of injury and trauma has prompted the implementation of the restraint chair as a safe, patient-centered alternative to seclusion and four-point mechanical restraints.

\section{Background}

Recent literature on seclusion and restraint primarily focuses on the effects of these events on both patients and staff. Additionally, there has been a call to eliminate or reduce the practice. While there have been successes in restraint and seclusion elimination in some areas, the prevalence of violence in forensic and intensive treatment psychiatric care facilities necessitates the continued use of these practices when all less restrictive interventions have proven unsuccessful (Duxbury, 2015). In these areas, the focus has shifted to the reduction of restraint or seclusion. The elimination of the practices as a consequence of behavior remains the goal while allowing for the use of restraint or seclusion in situations of imminent danger (Maguire, Young, \& Martin, 2012). 
Restraint and seclusion techniques traditionally include supine restraint on a bed in fourpoint mechanical restraints, physical holds (vertically, supine or prone) to secure patients or to administer medication, and seclusion in the form of isolation in a locked room. Often, a prone hold is used to secure the patient prior to four-point mechanical restraint or seclusion and has been associated with less staff injury due to the position of the patient (Sloane et al., 2014; Hollins, 2010). In forensic and intensive treatment units, patients may be admitted against their will, have histories of violence, and may possess antisocial behavior and have limited skills to manage aggressive outbursts (Maguire et al., 2012). In these situations, violence may occur before a therapeutic relationship with the patient can be established, requiring restraint or seclusion to reduce the risk of injury (Maguire et al., 2012). Calegaro and colleagues (2014) recognize the increase in aggressive behavior in the first 24 hours of admission and attribute the increase to severe hallucinations and delusions, which can drive chaotic physical aggression.

\section{Physical Injury}

The prevalence of violence in patients on forensic and intensive treatment psychiatric units is reflected in the high rates of injury amongst psychiatric nurses (Lanza, Rierdan, \& Zeiss, 2006). A study by Moylan and Cullinan (2011) showed that in a sample of 110 nurses, $80 \%$ of the nurses had been assaulted by unrestrained patients, with harm ranging from eye injuries to permanent disability. Unfortunately, restraint and seclusion have the potential to endanger the patient as well. As a result of seclusion or restraints, patients have sustained injuries ranging from minor bruising to muscle atrophy and, in some cases, death (Berzlanovich, Schopfer, \& Keil, 2012). A study of Pennsylvania's forensic service centers over a ten-year period showed $13 \%$ of the containment events resulted in patient injuries such as bruising or abrasions while $0.8 \%$ resulted in patients receiving lacerations that required sutures (Smith et al., 2015). Injuries 
from restraint and seclusion have been tied to improper monitoring of the patient, strap placement in four-point mechanical restraints, and positional asphyxiation (Berzlanovich et al., 2012; Lancaster, Whittington, Lane, Riley, \& Meehan, 2008).

Patient injury or death due to positional asphyxiation has been a primary focus of restraint safety in recent years since The Hartford Courant reported the high incidents of death due to restraints in 1998 (Altimari \& Weiss, 1998). In the 1998 article, Altimari and Weiss pointed to the prone restraint hold as a contributing factor. Positional asphyxia occurs when the body's position prevents adequate breathing and is most often associated with the "face-down" technique of the prone restraint (Hollins, 2010). Obesity is a contributing factor to the risk of positional asphyxiation in prone restraints. Unfortunately, due to the weight gain associated with atypical antipsychotic medications, this contributing factor is a serious concern for psychiatric patients (Hollins, 2010). With the elimination of the prone restraint practice, staff injuries have become a significant focus as evidence suggests that staff injury is less likely to occur with prone restraints (Lancaster et al., 2008).

\section{Psychological Injury}

The adverse psychological effects of seclusion and restraint use are prevalent for both patients and staff. Mohler and Meyer (2014) conducted a literature review of nurses' attitudes regarding physical restraint use in geriatric care. Results indicated nurses struggle with moral issues around implementing restraints, noting predominantly negative feelings toward their use, yet feeling a need to use them. A review of nurses' attitudes on the use of seclusion indicated they feel it is necessary to manage incidents of violence (Happell \& Harrow, 2010). Nurses have mixed feelings about the use of seclusion and restraints, causing them to psychologically struggle with the process. 
Psychological effects of seclusion and restraint on the patient are less conflicted than for the staff. A review of the literature on the patient perspective of seclusion found patients' experience to be primarily negative, with a few reporting the seclusion experience was helpful (Van Der Merwe, Muir-Cochrane, Jones, Tziggili, \& Bowers, 2013). Strout (2010) conducted a review of the qualitative literature around the patient experience of being physically restrained. Findings indicated four main themes, which were predominantly negative including the feeling of being re-traumatized, negative psychological implications, the sensation of a broken spirit, and a perception the restraint process was unethical (Strout, 2010).

\section{The Restraint Chair}

The restraint chair has been identified as an intervention with the potential to benefit both patients and staff with reduced injury rates while improving patient outcomes related to emergency restraint. Introduction of the restraint chair provides patients and staff an alternative to traditional four-point mechanical restraint or seclusion. While four-point mechanical restraint and seclusion continue to be utilized, the availability of the restraint chair offers an additional resource to implement based upon the nurse's assessment of the situation and the needs of the patient, which focuses on maximizing the patient's sense of personal control and dignity in a humane manner.

Currently, there is limited literature regarding the restraint chair, which has been attributed to the fact that it originated as a law enforcement tool, not a medical device (Castillo, Coyne, Chan, Hall, \& Vilke, 2015). In law enforcement and corrections, few risks have been directly related to the use of the restraint chair and available medical literature suggests that deaths associated with the use of the restraint chair have occurred for reasons other than the chair itself (Castillo et al., 2015). Proper use of the restraint chair requires constant observation of the 
patient while in the chair with nursing assessment occurring every fifteen minutes (Connor, 2007). Further recommendations include periodic range of motion release and full release from the restaint chair every two hours for comfort measures such as toileting and fluids (Connor, 2007).

The ability to have patients in an upright position provides for ease of control for nursing staff during emergency situations while reducing the risk to patients by not resulting in changes to oxygen saturation of the restrained patient (Castillo et al., 2015). The position of the patient could also contribute to a shorter restraint episode. Gildberg and colleagues (2015) recognize that restraint episodes are shortened when supporting factors provided by the staff in the form of expectations, validating positive behavior, and developing a therapeutic relationship are present. The sitting position allowed by the restraint chair is thought to facilitate the effectiveness of supportive factors by providing the patient the ability to remain in a comfortable, eye-to-eye position with staff, as opposed to the submissive supine position of four-point mechanical restraint or the isolation of seclusion. The ongoing implementation of de-escalation and calming techniques are important to developing the therapeutic relationship and reducing the risk of further violent behavior (Bilici, Sercan, \& Tufan, 2013).

Due to the paucity of literature assessing its safety and effectiveness in clinical settings, the purpose of this research was to determine if the restraint chair resulted in shorter episode durations, fewer patient and staff injuries, and a greater percentage of patients accepting medications by mouth compared to the traditional methods of restraint (four-point mechanical restraint and seclusion).

\section{Methods}




\section{Ethical Considerations}

Data from all restraint cases between May 1, 2014 and May 1, 2015 was collected from a retrospective chart review of three large psychiatric institutions in the northeastern United States. All protected Health Information (PHI) was removed, subjects were coded with a Case ID to ensure anonymity, and information was entered into a secure database shared by all three institutions. Institutional Review Board (IRB) approval was obtained from each hospital.

\section{Data Collection}

The retrospective chart review included all cases where a patient was restrained by one of the following methods: four-point mechanical restraints, seclusion, or the restraint chair. Episodes where the patient was under the age of 18 and patients who were restrained in order to administer court ordered treatments were excluded from the study. The primary discharge diagnosis was also collected. Primary discharge diagnoses coded for the study included: schizophrenia, schizoaffective disorder, bipolar disorder, psychosis, mood disorder, and major depressive disorder. If patients were discharged with other diagnoses, they were coded under the term "other diagnosis." Diagnoses included under the category "other diagnosis" were substance use disorders, post-traumatic stress disorder (PTSD), anxiety disorders, and cognitive disorders among others. Additional variables collected on each case included: age of the patient, gender of the patient, episode duration, medication and route of administration during the restraint episode, as well as injuries sustained by the patient or staff members involved in the restraint episode.

The three United States hospitals collaborating on this study were XXX Hospital in Rhode Island, XXX in Connecticut, and XXX Hospital in Massachusetts. The restraint chair was introduced in XXX Hospital in 2012, followed by IOL and XXX Hospital in 2013. At XXX Hospital, two Intensive Treatment Units (ITUs), with a combined 46 beds were included in the 
chart review. These units specialize in treating patients with psychotic disorders, bipolar disorder, and personality disorders for patients between the ages of 18-64. The XXX chart analysis included three adult units, each with 20-24 beds that treat patients between the ages of 18-60 years. One of the included units at IOL primarily covers general adult psychiatric disorders, while the second provides care for chronic psychotic illnesses, and the third treats personality disorders. At XXX Hospital, one 28 bed adult unit specializing in the treatment of bipolar and psychotic disorders was included in the study.

\section{Hypotheses}

The study had four research hypotheses: 1) patients who are restrained in the restraint chair will spend less time in restraints than patients who are restrained by either four-point mechanical restraint or LDS; 2) the proportion of patients more likely to accept medications by mouth rather than by the intramuscular (IM) route will be higher in the restraint chair; 3) patients will have fewer injuries with the use of the restraint chair compared to four-point mechanical restraint and seclusion; and 4) staff will have fewer injuries with the use of the restraint chair compared to four-point mechanical restraint or seclusion.

\section{Data Analysis}

Hypothesis one was tested using a regression model, the dependent variable being the logarithmic transformation of time (in minutes) spent, so the results were presented as the ratio of mean time spent in restraint. It is often called RR (rate ratio). The independent variables originally included in the model were age, gender, diagnosis (schizophrenia, schizoaffective, bipolar, psychosis, mood disorder, major depression, and "other diagnosis"), and medications prescribed (haloperidol, lorazepam, chlorpromazine, benztropine, olanzapine, fluphenazine, and diphenhydramine). Stepwise model selection procedure, however, was utilized to establish the 
final set of independent variables. Hypotheses two, three, and four were assessed using logistic regression analysis yielding odds ratios (ORs) for comparisons. Data analysis was completed using SAS 9.4 software.

\section{Results}

The entire sample consisted of 743 cases of restraint that were divided by restraint method as follows: 332 cases of restraint chair, 310 cases of seclusion, and 101 cases of fourpoint mechanical restraint. For the entire sample $(n=743)$, the mean age was $32.3(S D=13.0)$ years, approximately half of the sample was female $(51.7 \%)$, and the mean time spent in restraint was $121.6(S D=233.1)$ minutes (see Table I). The most common discharge diagnoses included: schizoaffective disorder (36.54\%), mood disorders (15.5\%), and bipolar disorder (15.1\%) while the most commonly prescribed medications during restraint were lorazepam $(37.1 \%)$, haloperidol $(33.6 \%)$, and chlorpromazine $(21.3 \%)$.

\section{[INSERT TABLE I HERE]}

\section{Age}

Significant differences were found for the age of patients between the three restraint methods. Patients restrained by four-point mechanical restraint were significantly younger $(M=27.4, S D=12.0)$ than patients restrained by either the restraint chair $(M=33.2,14.0$, $\mathrm{p}<0.0001)$ or seclusion $(M=33.0, S D=12.0, \mathrm{p}<0.0001)$. See Table I.

\section{Time in Restraint}

The mean time spent in confinement for each mode of restraint was as follows: 104.6 $(S D=124.7)$ minutes for the restraint chair, $134.1(S D=274.8)$ minutes for seclusion, and 139.2 $(\mathrm{SD}=341.5)$ minutes for 4 point. When comparing the three modes of confinement, there were no significant differences $(p=0.44)$ found in the amount of time spent in restraint (see Table I). 
However, males spent $37 \%$ more time restrained than females $(R R=1.37, \mathrm{p}<0.0001)$. Patients who were prescribed haloperidol $(R R=1.41, p<0.0001)$, chlorpromazine $(R R=1.68, p<0.0001)$, and benztropine $(R R=2.03, p=0.0037)$ spent a longer amount of time restrained, compared to those not prescribed these medications. Furthermore, those who were diagnosed with mood disorders $(R R=0.57, p<0.0001)$, psychosis $(R R=0.50, p<0.0001)$ and "other diagnosis" $(\mathrm{RR}=0.69, \mathrm{p}=0.0002)$ spent less time restrained compared to those diagnosed with schizophrenia, schizoaffective disorder, bipolar disorder, and major depressive disorder.

\section{Route of Medication Administration}

In terms of the route of administration for medications, proportions of patients receiving medications by mouth were compared across the three restraint methods. Those in restraint chair were more likely to receive medication by mouth than those restrained in four-point mechanical restraints ( $O R=1.83,95 \%$ CI [1.02-3.31], $p=0.044)$. However, patients restrained by seclusion were more likely to receive medications by mouth than those restrained in the restraint chair $(O R=2.51,95 \%$ CI [1.72-3.68], $p<0.0001)$ or those restrained by four-point mechanical restraint $(\mathrm{OR}=4.61,95 \%$ CI $[2.54-8.38], p<0.0001)$.

When looking at medication type, certain medications showed a higher likelihood of administration by mouth in the regression analysis. Medications with a higher likelihood of oral administration included: haloperidol $(p<.0001)$, chlorpromazine $(p<.0001)$, benztropine ( $p=0.001)$, olanzapine $(p=0.0494)$, and fluphenazine $(p=0.0008)$. Some patient factors were found to be less likely to receive medication by mouth; these included patients who were older $(p<0.0001)$ and those with a discharge diagnosis of bipolar disorder $(p=0.0045)$.

\section{Patient and Staff Injury}


The proportion of patient injury among the three confinement methods was found to be similar. However, patients with a discharge diagnosis of schizophrenia (OR=3.11, 95\% CI [1.12$8.62], p=0.0292)$ and those who received haloperidol $(\mathrm{OR}=3.24,95 \%$ CI $[1.24-8.51], p=0.0169)$ were more likely to experience injury. Staff injury proportions between the three confinement methods were significantly different. Patients restrained by four-point mechanical restraint were more likely to cause staff injury than those in the restraint chair (OR=4.32, 95\% CI [1.56-11.95], $p=0.0048)$ or by seclusion $(\mathrm{OR}=8.10,95 \% \mathrm{CI}[2.40-27.29], p=0.0007)$. Additionally, staff injury was more likely if the patient was older $(\mathrm{p}=0.0113)$, had a discharge diagnosis of schizophrenia $(p=0.0005)$, or was prescribed haloperidol $(\mathrm{p}=0.0004)$, chlorpromazine $(\mathrm{p}=0.0021)$, benztropine $(\mathrm{p}=0.0073)$ or olanzapine $(\mathrm{p}=0.0009)$ during the restraint episode.

The percentage of injuries by restraint type was low for both patients and staff in this study. Out of the 332 episodes involving the restraint chair, $5(1.5 \%)$ had patient injuries and 13 (3.9\%) had staff injuries. Among the 101 episodes of four-point mechanical restraint, 3 (3.0\%) involved patient injuries and 9 (8.9\%) involved staff injuries. Finally, for the 310 episodes of seclusion, $11(3.5 \%)$ had patient injuries and $6(1.9 \%)$ had staff injuries. Please see Tables II and III for the types of patient and staff injuries by restraint method.

[INSERT TABLES II \& III HERE]

\section{Discussion}

The present study sought to compare three methods of restraint to determine if one of the three methods resulted in shorter durations, fewer patient and staff injuries, and a greater percentage of patients to receive medication by mouth rather than by injection. This retrospective chart review looked at 743 cases of which: $44.7 \%$ were cases of restraint chair, $41.7 \%$ cases of seclusion, and $13.6 \%$ cases of four-point mechanical restraint. The variations in the percentage of 
interventions applied during the study period indicate that there could be a cultural shift away from four-point mechanical restraint. The present study found those who were restrained by four-point mechanical restraint had a significantly younger mean age compared to those restrained with the restraint chair or secluded in locked door quiet rooms. The literature suggests that age, gender, diagnosis and familiarity with the patient are characteristics that the nurse considers in addition to the risk of harm when choosing to restrain a patient (Lindsey, 2009). Nurses' have also indicated a reluctance to restrain older adults (Lindsey, 2009), which might be a reflection of what we are seeing in the data from this study.

\section{Time in Restraint}

Episode durations are a critical measure in determining the effectiveness of an intervention. Events with shorter durations are associated with an ability of patients to regain control in less time and return to the milieu. The lower mean time spent in restraint via the restraint chair compared to the two other methods of restraint was no surprise to the authors as informal reports from nursing staff before the study indicated patients were ready for release from the restraint chair sooner than from the other two methods. One possible explanation for the lack of significant difference in mean restraint time between the three methods could be derived from the fact that there were some patients with long duration episodes, which may have caused the findings to be statistically non-significant.

\section{Medication Administration}

A patient receiving medications by mouth indicates a voluntary acceptance of medication treatment and is preferred over the intrusive intramuscular administration of medication. In addition to the patient's willingness to receive medication, factors related to experience of nursing staff, attitudes toward aggressive patients, prescribing practices of providers, as well as 
state laws regarding involuntary injections could also impact the route of administration of medication to patients in restraint or seclusion. Results in this study indicated the likelihood of receiving medication by mouth was greatest in seclusion, followed by the restraint chair with four-point mechanical restraint the least likely to receive medication by mouth.

One way to consider the differences seen in route of medication administration might be to think of the restraint methods as the most to least restrictive means with four-point mechanical restraints being the most restrictive and seclusion being the least. This places the restraint chair in the middle. Further, as compared to four-point restraints, the patient is in an upright position when placed in the restraint chair, thus making it more conducive to taking medications by mouth. When considered as a matter of most to least restrictive means, nurses will choose the means that fit the riskiness of the behaviors presented by the patient. Patients who are at highest risk of harm to self or others will be placed in the most restrictive means (four-point mechanical restraint). These patients are probably the least able to exhibit personal control, requiring medication administration in an intramuscular, involuntary manner.

\section{Patient and Staff Injuries}

Physical injuries to patients during restraint and seclusion are a source of concern and a driving force behind efforts for eliminate the practice. As noted by Lancaster and colleagues (2008), with the elimination of prone restraints, staff injuries have also become a concern. When the restraint chair, seclusion and four-point mechanical restraints were compared in this study, no significant differences in the proportion of patient injuries among the three confinement methods were found.

Significant differences in staff injuries were identified in this study. More staff injuries occurred during episodes of four-point mechanical restraint than by seclusion or by the restraint 
chair. The higher risk for staff injury with four-point mechanical restraints could be a factor in the reduced amount of use for this restraint method compared to the other two methods available to nurses in this study.

One possible explanation for the difference seen in the percentage of staff injured by restraint method may be that those in seclusion are often able to walk into the seclusion room on their own. They may be less combative, resulting in fewer injuries for the staff. The restraint chair requires a higher degree of staff physical intervention with the patient compared to seclusion, through assistance in sitting in the chair and securing the tie downs, but less intervention compared to four-point mechanical restraint where the patient must be in a supine position. These differences in how the three methods are implemented, may account for the differences seen in staff injury across the three restraint types.

\section{Strengths and Limitations}

Results of this study are derived from the synthesis of data across three psychiatric hospitals, allowing for greater generalizability of findings. The multi-site aspect of this study permitted the gathering of 743 episodes of restraint or seclusion to be analyzed through the retrospective chart review of events occurring over a year's time. In addition to the large sample size, the partnership between the three institutions enabled the researchers to include samples from a variety of populations. $\mathrm{XXX}$ is located in $\mathrm{XXX}, \mathrm{MA}$ and primarily serves clients from the $\mathrm{XXX}$ area. $\mathrm{XXX}$ is located in $\mathrm{XXX}, \mathrm{CT}$ and serves clients from this urban city. $\mathrm{XXX}$ Hospital is in a suburban area of XXX, RI and serves a fair mix of patients from both the urban and suburban areas that surround the city. Utilizing data from three institutions allows for better generalizability of results due to the mixed nature of the populations served. 
A limitation of the present study involves the inclusion of individuals, which could be considered 'outliers.' Early in the design process, it was decided to include all cases of restraint, regardless of how frequently the patient had been hospitalized or if the patient had multiple episodes of restraint and/or seclusion. Prior work on restraint has indicated some patients are more frequently restrained than others and we felt it was important to include these individuals in the data analysis (Beck et al., 2008).

\section{Suggestions for Future Research}

Future research on restraint use would benefit from the inclusion of the patient and staff perspectives. Incorporating information about the event that prompted the intervention and the rationale for the use of seclusion or restraint by the nurse would aid in the understanding of how methods of restraint are selected. The patient perspective would allow us to understand the psychological effects each method has on the person being restrained. Finally, these perspectives may help to clarify differences in episode duration and elucidate why staff injury rates vary by restraint method.

Another consideration for future work involves gathering more data about the unit where the restraint took place. Differences in hospital policy, training methods, culture, and staffing could impact the frequency of seclusion and restraint events as well as which intervention is chosen. Gathering information on the timing of the events, the shift, the staffing ratios and the years of experience of the nursing staff may help to determine if events occurred due to hospital or unit factors rather than patient factors.

\section{Conclusion}

This study aimed to compare three methods of seclusion and restraint, including the newly introduced restraint chair. Currently, there is a dearth of literature on the safety and 
effectiveness of the restraint chair in clinical settings. Findings of this study indicate that the restraint chair is no more likely to cause patient injury than four-point mechanical restraint or seclusion. Additionally, the restraint chair resulted in a lower chance of staff injury when compared to episodes of four-point mechanical restraint. It is widely agreed that current practices in inpatient psychiatric care are moving towards elimination of restraint and seclusion. This study acknowledges this while seeking to provide evidence and understanding of the available methods of restraint and seclusion currently in use. By gaining an appreciation of the safety and patient centered use of the restraint chair during violent episodes, this study aims to contribute to the overall goal of identifying the unique needs of psychiatric patients in intensive treatment and reduce the use of more intrusive methods of de-escalation. 


\section{References}

Altimari, D., \& Weiss, E. M. (1998, October 17). Reform urged in use of restraints. The Hartford Courant. Retrieved from: http://articles.courant.com/1998-1017/news/9810170180_1_mental-retardation-psychiatric-restraints

APNA Board of Directors. (2014, April 8). APNA position on the use of seclusion and restraint. Retrieved from: http://www.apna.org/i4a/pages/index.cfm?pageid=3728

Beck, N. C., Durrett, C., Stinson, J., Coleman, J., Stuve, P., \& Menditto, A. (2008). Trajectories of seclusion and restraint use at a state psychiatric hospital. Psychiatric Services, 59(9), $1027-1032$.

Berzlanovich, A. M., Schopfer, J., \& Keil, W. (2012). Deaths due to physical restraint. Deutsches Arzteblatt International , 109 (3), 27-32.

Bilici, R., Sercan, M., \& Tufan, A. E. (2013). Assaualtiveness in psychiatric patients and approach to assaultive patients. Journal of Psychiatry and Neurological Sciences , 26 (2), 190-198.

Calegaro, V. C., Dotto, A. B., Freitas, D., Brum, A. B., Valerio, A. G., Schetinger, C. C., et al. (2014). Agressive behavior during the first 24 hours of psychiatric admission. Trends in psychiatry and psychotherapy, 36 (3), 152-159.

Castillo, E. M., Coyne, C. J., Chan, T. C., Hall, C. A., \& Vilke, G. M. (2015). Review of the medical and legal literature on restraint chairs. Journal of Forensic and Legal Medicine , 33, 91-97.

Connor, G. (2007). "Top ten" elements in restraint chair procedures. American Jails, 58-60.

Duxbury, J. A. (2015). The Eileen Skellern lecture 2014: Physical restraint: In defence of the indefensible? Journal of Psychiatric and Mental Health Nursing , 22, 92-101. 
Gildberg, F. A., Fristed, P., Makransky, G., Moeller, E. H., Nielsen, L. D., \& Bradley, S. K. (2015). As time goes by: Reasons and characteristics of prolonged spisodes of mechanical restraint in forensic psychiatry. Journal of Forensic Nursing , 11 (1), 41-50.

Happell, B., \& Harrow, A. (2010). Nurses' attitudes to the use of seclusion: A review of the literature. International Journal of Mental Health Nursing, 19(3), 162-168. doi: 10.1111/j.1447-0349.2010.00669.x.

Hollins, L. (2010). Managing the risks of phsycial intervention: Developing a more inclusive approach. Journal of Psychiatric and Mental Health Nursing , 17, 369-376.

Kontio, R., Joffe, G., Putkonen, H., Kuosmanen, L., Hane, K., Holi, M., \& Valimaki, M. (2010). Seclusion and restraint in psychiatry: Patients' experiences and practical suggestions on how to improve practices and use alternatives. Perspectives in Psychiatric Care , 48, 1624.

Lancaster, G. A., Whittington, R., Lane, S., Riley, D., \& Meehan, C. (2008). Does the position of restraint of disturbed psychiatric patients have any association with staff and patient injuries? Journal of Psychiatric and Mental Health Nursing , 15, 306-312.

Lanza, M. L., Rierdan, J., \& Zeiss, R. (2006). Violence against psychiatric nurses: Sensitive research as science and intervention. Contemporary Nurse , 21 (1), 71.

Lindsey, P. L. (2009). Psychiatric Nurses' Decision to Restrain: The association between empowerment and individual factors. Journal of Psychosocial Nursing, 47(9), 41-49.

Maguire, T., Young, R., \& Martin, T. (2012). Seclusion reduction in a forensic mental health setting. Journal of Psychiatric and Mental Health Nursing , 19, 97-106. 
Mohler, R., \& Meyer, G. (2014). Attitudes of nurses towards the use of physical restraints in geriatric care: A systematic review of qualitative and quantitative studies. International Journal of Nursing Studies, 51(2), 274-288

Moylan, L. B., \& Cullinan, M. (2011). Frequency of assault and severity of injury of psychiatric nurses in relation to the nurses' decision to restrain. Journal of Psychiatric and Mental Health Nursing , 18, 526-534.

Sloane, C., Chan, T. C., Kolkhorst, F., Newman, T., Castillo, E. M., \& Vilke, G. M. (2014). Evaluation of the ventilatroy effects of the prone manimum restraint (PMR) position on obese human subjects. Forensic Science International , 237, 86-89.

Smith, G. M., Ashbridge, D. M., Altenor, A., Steinmetz, W., Davis, R. H., Mader, P., \& Adair, D. K. (2015, December). Relationship Between Seclusion and Restraint Reduction and Assaults in Pennsylvania's Forensic Services Centers: 2001-2010. Psychiatric Services, $66(12)$.

Strout, T. (2010). The experience of being physically restrained: An integrative review of the qualitative literature. International Journal of Mental Health Nursing, 19(6), 416427. doi: 10.1111/j.1447-0349.2010.00694.x.

Van Der Merwe, M., Muir-Cochrane, E., Jones, J., Tziggili, M., \& Bowers, L. (2013). Improving seclusion practice: Implications of a review of staff and patient views. Journal of Psychiatric and Mental Health Nursing, 20, 203-215. doi: 10.1111/j.13652850.2012.01903.x 